\title{
Commentary \\ Acute lung injury outside the ICU: a significant problem
}

\section{Simon J Finney and Timothy W Evans}

Department of Critical Care, Imperial College School of Medicine, Royal Brompton Hospital, SW3 6NP, London, UK

Corresponding author: Timothy W Evans, t.evans@rbht.nhs.uk

Published: 26 October 2007

Critical Care 2007, 11:169 (doi:10.1186/cc6128)

This article is online at http://ccforum.com/content/11/5/169

(C) 2007 BioMed Central Ltd

See related research by Ferguson et al., http://ccforum.com/content/11/5/R96

\begin{abstract}
The incidence of acute lung injury (ALI) is influenced by nature of the underlying clinical condition. The frequency with which $A L I$ is likely to be encountered by those practicing outside the intensive care unit (ICU) setting is largely unknown. Data from the paper under discussion [1] indicates that $A L I$ is seen relatively frequently in general wards and can be managed there until death or recovery. In patients with predisposing illnesses directly involving the lung, progression to ALI can be rapid.
\end{abstract}

Acute lung injury (ALI) and its extreme manifestation, the acute respiratory distress syndrome (ARDS) complicate a wide variety of serious medical and surgical conditions, not all of which affect the lung directly [2]. ALI and ARDS are defined by varying degrees of refractory hypoxemia seen in association with bilateral lung infiltrates on chest radiography; in the absence of left atrial hypertension (thereby excluding hydrostatic pulmonary oedema as a cause), but in the presence of a clinical condition known to precipitate the syndrome. Patients can present with either ALI or full-blown ARDS, which may have prognostic significance. Some 35\% of patients with ALI seem to develop ARDS within three days of intensive care unit (ICU) admission [3].

Early estimates of the incidence of ARDS varied from 1.5 to 75 cases per 100,000 population - the considerable variation being attributable in part to the lack of accepted and widely applied defining criteria. However, the introduction of the consensus definitions [2] facilitated the reporting of incidences for ARDS of between 4.8 and 34 per 100,000 population per year, with significant variability internationally [4]. By contrast, a recent prospective, population-based cohort study in a single US county found the incidence of ALI to be higher (78.9 per 100,000 population) and to increase with age, suggesting some 190,600 cases occur in the USA alone each year [5].
The incidence of ARDS is influenced by the underlying clinical condition [6]. Moreover, the extent to which the precipitating condition afflicts the lung directly or indirectly seems to influence lung compliance and recruitment, appearances on computed tomography, and possibly clinical outcome [7,8]. However, epidemiological data concerning ALI/ARDS and predefined clinical conditions in terms of incidence and temporal association are sparse and emerged before the consensus definitions were developed. A paper published in this issue of the journal by Ferguson and colleagues [1] redresses this imbalance. In a prospective study conducted over four months in three hospitals in Spain, the highest incidence of lung injury was identified in patients with shock (35.6\%) and pneumonia (9.5\%). Direct (pulmonary) risk factors were identified in $30 \%$ of the cases of ALI and ARDS identified, which developed in 6.5\% and $4.3 \%$ of the index population respectively. The onset of lung injury was more rapid in those with direct (median 0 days) than indirect (median three days) insults. Mortality was higher in those who developed lung injury (ALI 25\%, ARDS 22.2\%) than those who did not (10.3\%). More surprisingly mortality amongst those with ALI did not differ if they were managed inside or outside the intensive care unit (ICU).

How robust are these data and how do they add to our knowledge? First, the index population was relatively small $(n=815)$, of whom only 53 developed ALI; 33 of these fulfilled the defining criteria for ARDS. Consequently, the authors were wise to avoid the temptation of subdividing patients according to predisposing illness more specific than 'pulmonary' or 'extra pulmonary'. Moreover, whilst identification of overall incidence and mortality from ALI were not primary aims of the study, the small numbers of patients afflicted means establishing population comparability is difficult, a fact acknowledged by the authors. Second, estimating with precision how frequently $\mathrm{ALI}$ develops and is

$\mathrm{ALI}=$ acute lung injury; ARDS = acute respiratory distress syndrome; $I C U=$ intensive care unit. 
managed clinically on the general wards is difficult because of uncontrollable variables such as the numbers and availability of ICU beds, referral practice within the institution, and case mix.

Despite these limitations, potentially important messages do emerge. First, it seems that in these institutions, significant numbers of patients with $\mathrm{ALI}$ are present on the general wards, suggesting that previous studies of overall incidence of ALI based on 'captive', ICU-based populations are likely to be inaccurate. More importantly, a proportion of these patients seem to be managed there until recovery or death. Whether this is desirable or not remains unclear. Thus, whilst mortality did not seem to differ, small numbers again make meaningful comparison between the ICU and non-ICU groups impossible. Second, the time course from clinical insult to ICU admission was substantially shorter than previously recorded and underlines the need for rapid recognition of, and intervention in, such cases. Further, the onset of lung injury was apparently more rapid in those with direct pulmonary insults, although whether this was because frequent respiratory evaluation with chest radiography and arterial gas analysis is more likely in those with pneumonia as opposed to say, non pulmonary sepsis, is unclear.

What is the take home message from this study for clinicians? As with all the best studies, more questions emerged than were answered. However, the potential importance of ALI emerging in the non-ICU setting should be recognised by those practicing outside the critical care environment. This is especially so concerning pulmonary predisposing illnesses, in which the progression to ALI can clearly be rapid.

\section{Competing interests}

The authors declare that they have no competing interests.

\section{References}

1. Ferguson ND, Frutos-Vivar F, Esteban A, Gordo F, Honrubia T, Peñuelas O, Algora A, García G, Bustos A, Rodríguez I: Clinical risk conditions for acute lung injury in the intensive care unit and hospital ward: a prospective observational study. Crit Care 2007, 11:R96.

2. Bernard GR, Artigas A, Brigham KL, Carlet J, Falke K: The American-European Consensus Conference on ARDS. Definitions, mechanisms, relevant outcomes, and clinical trial coordination. Am J Respir Crit Care Med 1994, 149:818-824.

3. Brun-Buisson C, Minelli C, Bertolini G, Brazzi L: ALIVE Study Group. Epidemiology and outcome of acute lung injury in European intensive care units. Results from the ALIVE study. Intensive Care Med 2004, 30:51-61.

4. Goss CH, Brower RG, Hudson LD, Rubenfeld GD; ARDS Network. Incidence of acute lung injury in the United States. Crit Care Med 2003, 31:1607-1611.

5. Rubenfeld GD, Caldwell E, Peabody E, Weaver J, Martin DP, Neff $M$, Stern EJ, Hudson LD. Incidence and outcomes of acute lung injury. N Engl J Med 2005, 353:1685-1693.

6. MacCallum NS, Evans TW. Epidemiology of Acute Lung Injury. Curr Opin Crit Care 2005, 11:43-49.

7. Gattinoni L, Caironi P, Cressoni M, Chiumello D, Ranieri VM, Quintel M, Russo S, Patroniti N, Cornejo R, Bugedo G. Lung recruitment in patients with the acute respiratory distress syndrome. N Engl J Med 2006, 354:1775-1786.
8. Suntharalingam G, Regan K, Keogh BF, Morgan CJ, Evans TW. Influence of direct and indirect etiology on acute outcome and 6-month functional recovery in acute respiratory distress syndrome. Crit Care Med 2001, 29:562-566. 